\title{
Quantification of Afghan Saffron's Moisture and Main Compounds (Crocin, Picrocrocin and Safranal) for Quality Evaluation
}

\author{
Raihana Halim $^{1,2 *}$, Najia Sherzay ${ }^{1,3 \oplus}$, Nazifa Faqeryar ${ }^{4} \oplus$, M. Homayoun Hashimi ${ }^{1} \oplus$ \\ ${ }^{1}$ Department of Biochemistry, Faculty of Pharmacy, Kabul University, Kabul, Afghanistan \\ 2 Department of Biotechnology, Institute of Natural Science, Çukurova University, Adana, Turkey \\ 3 Institute of Pathology, Laboratory and Forensic Medicine (I-PPerForM), Universiti Teknologi MARA, 47000, \\ Sungai Buloh, Selangor, Malaysia \\ 4 Avignon University, INRAE, UMR408, GREEN Extraction Team, 84000, Avignon, France \\ ${ }^{*}$ Corresponding author: halimraihana@gmail.com
}

\begin{abstract}
Saffron, the stigmas of the plant Crocus sativus L., has attracted the worldwide interest for its specific organoleptic and pharmacological characteristics. Cultivation of saffron in Afghanistan began in recent years and in very short time Afghan saffron hit higher record. Till now, there is no scientific study which has analyzed its characteristics according to ISO methods. In this study, the main components of Afghan saffron have been described, and quality parameters along with its characteristics were analyzed according to ISO-3632-2 test methods. The results of moisture analysis (5.12 to 5.74\%) and determination of crocin (230.52255.15) of Afghan saffron were at the range of standard as described for category I of saffron in ISO 3632-2 test methods. However, the results of some samples for safranal and picrocrocin (38.52-40.21 for safranal and 68.86-72.63 for picrocrocin) were higher than the range of category I of ISO 3632-2.
\end{abstract}

Keywords: Afghans saffron, moisture, bioactive compounds, ISO 3632-2

\section{Introduction}

Saffron, the plant Crocus sativus L., is a member of the family Iridaceae; the dried stigmas of this plant with dark red color and trumpet-shaped are some of the world's most expensive spices (Jan et al., 2014). Few spices can provide a combination of color, taste, and aroma and the most popular of these is saffron (García-Rodríguez et al., 2014).

In ancient times, saffron was mainly used for dyeing such as dyeing silk and other textiles, and it is still used as a cosmetic and food colorant (Tsatsaroni \& Eleftheriadis, 2008), but recent studies have also concentrated on its medical properties such as, antidepressant, antispasmodic, antidiabetic, anticancer, aphrodisiac and expectorant (Abdullaev, 2002; Manzo et al., 2015; Sereshti et al., 2014; Jan et al., 2014; Melnyk et al., 2010; Sanchez et al., 2008). Saffron contains more than 150 volatile and non-volatile components (Padmavathy et al., 2011), but three major bioactive compounds of saffron are crocin, picrocrocin (Gikas et al., 2021) and 
safranal which are responsible for color, taste, and aroma, respectively; and saffron's quality depends on the concentration of these three main metabolites (Kiani et al., 2018; Sanchez et al., 2009; Sujata et al., 1992). Crocins are water-soluble carotenoid compounds related to the monoand di-glycosyl esters of polyene dicarboxylic acid (Lozano et al., 1999) which have shown to improve memory (Pitsikas et al., 2007), improve autoimmune disease, antioxidant, antiinflammatory (Korani et al., 2019), and antidepressant activities (Lee et al., 2015; Wang et al., 2010). Picrocrocin $\left(\mathrm{C}_{16} \mathrm{H}_{26} \mathrm{O}_{7}\right)$ is considered to be the main bitter principle of saffron. It is a monoterpene glycoside precursor of safranal (Lage \& Cantrell, 2009). Safranal is mainly an essential oil and is responsible for the odor of saffron. Chemically it is monoterpene aldehyde $\left(\mathrm{C}_{10} \mathrm{H}_{14} \mathrm{O}\right)$ which is formed during the drying and storage of the hydrolysis of picrocrocin. It is believed that this bioactive compound of saffron is responsible for its antioxidant, anticonvulsant, hypnotic, and anti-cancer effects (Chaudhari et al., 2013). These three metabolites are among the most important chemical factors in evaluating the nutritional and pharmacological quality of saffron (Bolandi et al., 2004; Zalacain et al., 2005; Zougagh, 2006). The moisture content of a food is dependent on species, variety, maturity of food and the relative humidity of the environment (Gazor \& Chaji, 2010). Therefore, the most important factors that affect the quality of the saffron during storage and can cause degradation and reduction of its quality are the product's moisture, relative humidity, ambient temperature, storage and light (Bolandi et al., 2004).

Global consumers of saffron give high importance to saffron's quality because on one hand, the quality can affect consumers' health (Sereshti et al., 2018), and on the other hand, due to its high price, it is susceptible to fraudulent practices (Petrakis \& Polissiou, 2017; Kiani et al., 2018).

These valuable plant species are cultivated in environments with very different climatic conditions and are well adapted to arid and semi-arid lands which produce stigmas annually. It is also adaptable to temperate and sub-tropical climates and can be grown on soils varying from sandy to well-drained clay loams (Isfahani et al., 2013; Lage \& Cantrell, 2009). Therefore, saffron is well suited to conditions in eastern Afghanistan, so it plays a major role in the country's socio-economical development (Peter, 2007).

Afghan saffron is a sustainable substitute crop with high value in some agricultural areas of Afghanistan for socio-economical development. Afghanistan is the 4th saffron producer in the world by producing significant amounts per year (average amount of 4 tons). In addition, Afghan saffron is the winner of the Superior Taste Awards from the International Taste \& Quality Institute- Brussels (Katawazy, 2013). Despite all these, Afghan saffron's characteristics are not well recognized, because there is not any written and published proof of its quality according to ISO standards. Even Afghanistan is not on the list of saffron-producing countries. Hence, this study aimed to analyze the quality parameters for Afghan saffron. If Afghan saffron is recognized as special because of its quality, producers could ask for more than buyers pay for saffron from other countries. To the best of the authors' knowledge, this is the first study that has evaluated the most important characteristics of Afghan saffron according to ISO-3632-2 (2011).

\section{Methodology}

Five samples (S1, S2, S3, S4, S5) were obtained from different wholesale saffron suppliers of Herat city with a guarantee of being free from adulteration on March 2019. The sampling was carried out according to the method described in ISO 948 and the samples were stored at $4{ }^{\circ} \mathrm{C}$ in the dark until the analysis was performed. Plastic bags were used for the packaging of saffron samples. All other necessary chemical reagents and some apparatus were supplied 
from chemical supplying companies in Kabul city. The samples were coded from 1 to 5 instead of using the names of the suppliers. The moisture content and main compounds of saffron (crocin, picrocrocin and safranal) determination were performed as indicated in ISO 3632-2 for quality evaluation of Afghan saffron. All tests were performed on samples from September to November 2019.

\section{Quality evaluation of saffron moisture and volatile matter content}

Moisture and volatile matter content is expressed as a percentage mass fraction of the sample. The test is performed as per ISO 3632-2. Around $2.5 \mathrm{~g}$ of the sample was weighed into the weighing dish. The uncovered weighing dish was placed into the oven maintained at $103^{\circ} \mathrm{C}$ and left for $16 \mathrm{~h}$. Then it was covered with a lid, and allowed to cool in the desiccator. After cooling, samples were weighed again to find the change in the moisture content. The test was performed two times for each sample and the average amount was used for analyzing test results.

The moisture and volatile matter content, $\mathrm{W}_{\mathrm{MV}}$, expressed as a percentage of the initial sample in Equation (1):

$$
W_{M V}=\left(m_{0}-m_{4}\right) \times \frac{100}{m_{0}} \%
$$

where

$m_{0}$ is the mass, in grams, of the test portion;

$m_{4}$ is the mass, in grams, of the dry residue.

\section{Quality evaluation of saffron by determining the main characteristics}

Tree main bioactive compounds of saffron, namely safranal, crocin and picrocrocin were analyzed in accordance with the spectrometric test method given in ISO 3632-2. Spectrophotometric assays were carried out with Shimadzu UV-1800 UV-Vis spectrophotometer (Shimadzu, Kyoto, Japan) using quartz cells of $1 \mathrm{~cm}$ path length. Absorbances were recorded between 200-700nm using the "photometric" function. All measurements were taken at room temperature.

Saffron stigmata were ground in a glass mortar and pestle. The ground saffron was passed through a $0.5 \mathrm{~mm}$ mesh. $500 \mathrm{mg}$ of ground saffron was transferred to a $1000 \mathrm{ml}$ balloon and $500 \mathrm{ml}$ of distilled water was added and mixed well. The mixture was agitated by magnetic stirrer for one hour in the dark. The volume was completed to $1 \mathrm{~L}$ with distilled water. $20 \mathrm{ml}$ of the mentioned solution was transferred to a $200 \mathrm{ml}$ balloon, and the volume was completed with the distilled water. The solution was then filtered by a membrane filter with a pore diameter of $0.45 \mu$.

The absorbance of the prepared solutions of all samples was evaluated at a wavelength of 330, 440 , and $257 \mathrm{~nm}$ for safranal, crocin, and picrocrocin; respectively. The spectrum of saffron in aqueous solution is illustrated in Figure 1 to show the peaks for safranal, crocin and picrocrocin at $200-700 \mathrm{~nm}$ range. 


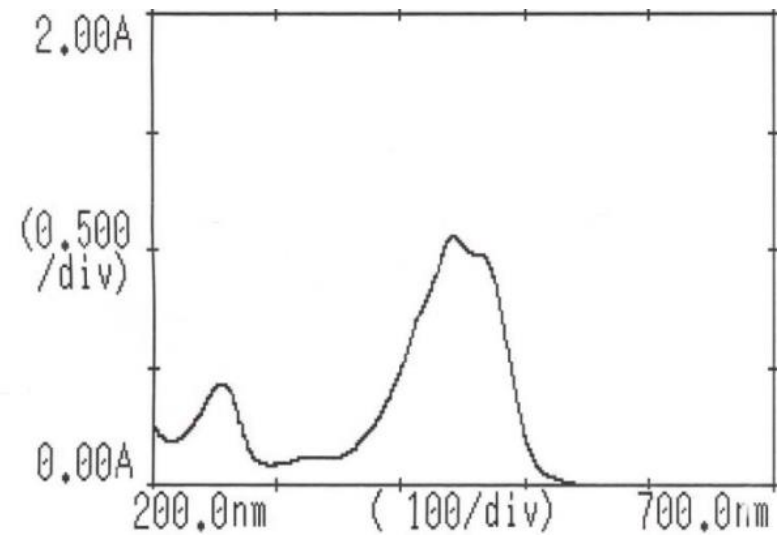

Figure 1. Spectrum of Afghan saffron in aqueous solution showing the peaks for safranal, crocin and picrocrocin at $200-700 \mathrm{~nm}$ range

\section{Statistical analysis}

Data were analyzed using GraphPad Prism 5.0 and results were expressed as mean and \pm SD.

\section{Results and Discussion}

\section{Moisture and volatile matter content test results}

The moisture content of saffron samples in our research ranged from 5.12 to $5.74 \%$ (Table 1). According to ISO-3632-2, the moisture content for Grade I should be less than $10 \%$; therefore, the percentage moisture and volatile matter content of Afghan saffron is in the range of Grade I. The moisture content of Grade I saffron from Greece was determined to be ranging from $5.49 \%$ to $9.96 \%$ (Maggi et al., 2011), the moisture content of Grade I saffron from Italy ranged from 5.35\% to 8.79\% (Giorgi et al., 2017); and for Grade I Spanish saffron the volatile contents were $5.49 \%$ to $10.43 \%$ (García-Rodríguez et al., 2017). According to another study (Azarabadi \& Özdemir, 2018), the moisture content of Iranian samples differed from $4.96 \%$ to $6.13 \%$.

\section{Bioactive compounds}

In all of our samples the results for bioactive compounds were between 230.52-255.15 for crocin, 38.52-40.21 for safranal, and 68.86-72.63 for picrocrocin; which are in the standard range according to the ISO-3632-2. In previous studies, the safranal content for Italian saffron were measured from 23.2 to 49 (Manzo et al., 2015); according to the research performed by GarcíaRodríguez et al., (2017) the safranal content of Greece saffron ranged between 29.81-45.55; safranal quantity of Iranian Grade I Saffron ranged between 30.00-43.64; safranal quantity in Spanish Saffron was between 28.58-46.07; and safranal quantity of Italian saffron ranged between 28.58-46.07. According to a study performed by Azarabadi and Özdemir (2018), the crocin amount of Iranian saffron was between 51.66 - $66.67 \mathrm{mg} / \mathrm{g}$ (Azarabadi \& Ozdemir, 2018). The highest crocin amount of Italian saffron was 234.90 (Manzo et al., 2015). Regarding the results of our study, the highest crocin amount of Afghan saffron is 255.15 which indicates the highest quality of Afghan saffron. As a result of another study, the picrocrocin amount of Italian saffron ranged from 81.30 to 113.00 which is close to Afghan saffron picrocrocin value. The high values of picrocrocin in Afghan saffron give the unique property to Afghan saffron worldwide. The values are presented in Table 2. 
Table 1. The quality parameters of Afghan saffron

\begin{tabular}{lllll}
\hline \multirow{2}{*}{$\begin{array}{l}\text { Sample } \\
\text { ID }\end{array}$} & $\begin{array}{l}\text { Moisture \& volatile } \\
\text { contents (\%) }\end{array}$ & \multicolumn{3}{c}{ Bioactive compounds } \\
\cline { 3 - 5 } & 5.45 & Crocin & Safranal & Picrocrocin \\
\hline S1 & 5.51 & 230.52 & 39.52 & 72.61 \\
S2 & 5.12 & 246.73 & 40.21 & 71.15 \\
S3 & 5.74 & 234.10 & 39.15 & 70.10 \\
S4 & 5.21 & 247.36 & 39.27 & 68.86 \\
S5 & 5.406 & 255.15 & 38.52 & 72.63 \\
\hline Mean & 0.247245 & 242.772 & 39.334 & 71.07 \\
Standard Deviation & 10.18879 & 0.612887 & 1.63069 \\
\hline
\end{tabular}

Table 2. Comparison of quality parameters of saffron from different countries

\begin{tabular}{lllll}
\hline \multirow{2}{*}{$\begin{array}{l}\text { Origin } \\
\text { country }\end{array}$} & Moisture \& volatile & \multicolumn{3}{c}{ Bioactive compounds } \\
\cline { 3 - 5 } contents (\%) & Crocin & Safranal & Picrocrocin \\
\hline Greece & $5.49-9.96$ & & $29.81-45.55$ & \\
Italy & $5.35-8.79$ & max. 234.90 & $23.2-49.00$ & $81.30-113.00$ \\
Spain & $5.49-10.43$ & & $28.58-46.07$ & \\
Iran & $4.96-6.13$ & $51.66-66.67$ & $30.00-43.64$ & \\
Afghan & $5.12-5.74$ & $230.52-255.15$ & $38.52-40.21$ & $68.86-72.63$ \\
\hline
\end{tabular}

\section{Conclusions}

Afghan Grade I saffron moisture and bioactive compounds has met all of the Grade I saffron characteristics of ISO 3632-2 test methods, with high flavoring and coloring strength due to the bioactive compounds. It has also proved that the region is most suitable for the cultivation of saffron therefore is a good choice for Afghan farmers to cultivate it. The results of the analysis of most samples show that Afghan saffron has high quality; however, this study is not sufficient and further research is needed. In order to be able to provide a separate identity for Afghan saffron, all other quality determination tests should be performed according to ISO 3632-2 methods.

\section{Acknowledgments}

The authors would like to thank the HEDP and World Bank for its financial support of this project.

\section{Author Statement}

The authors confirm contribution to the paper as follows: study conception and design: Raihana Halim, Najia Sherzay, Nazifa Faqeryar; data collection: Raihana Halim, Najia Sherzay, M. Homayoun Hashimi; analysis and interpretation of results: Raihana Halim, Najia Sherzay; draft manuscript preparation: Raihana Halim, Najia Sherzay, and Nazifa Faqeryar. All authors reviewed the results and approved the final version of the manuscript. 


\section{Conflict of Interest}

Example: The authors declare no conflict of interest.

\section{References}

Abdullaev, F. I. (2002). Cancer Chemopreventive and Tumoricidal Properties of Saffron (Crocus sativus L.). Experimental Biology and Medicine, 227(1), 20-25. doi: $10.1177 / 153537020222700104$

Azarabadi, N., \& Özdemir, F. (2018). Determination of Crocin Content and Volatile Components in Different Qualities of Iranian Saffron. Gida / The Journal of Food, 43(3), 476-489. doi.org/10.15237/gida.GD18018

Bolandi, M., Amin, L. M., Karbassi, A., Ghodousi, H. B., \& Mesbahi, G. (2004). Effect of Drying Methods and Light on the Cemical Characteristics of Saffron (Crocus Sativus L.) During storage. Agricultural Sciences and Technology, 18(2), 197-204.

Chaudhari, S. P., Bhandurge, N. B., Ratnaparkhi, M. P. (2013). Development and validation of UV spectrophotometric method of safranal. Pelagia Research Library. 4(4), 136-140.

García-Rodríguez, M. V., López-Córcoles, H., Alonso, G. L., Pappas, C. S., Polissiou, M. G., \& Tarantilis, P. A. (2017). Comparative evaluation of an ISO 3632 method and an HPLCDAD method for safranal quantity determination in saffron. Food Chemistry, 221, 838843. https:/ / doi.org/10.1016/j.foodchem.2016.11.089

García-Rodríguez, M. V., Serrano-Diaz, J., Tarantilis, P. A., López-Córcoles, H., Carmona, M., Alonso, G. L. (2014). Determination of Saffron Quality by High-Performance Liquid Chromatography. Journal of Agricultural and Food Chemistry, 62(32), 8068-8074. https:// doi.org/10.1021/jf5019356

Gazor, H. R., Chaji, H. (2010). Equilibrium moisture content and heat of desorption of saffron. International Journal of Food Science $\mathcal{E}$ Technology, 45(8), 1703-1709. https:// doi.org/10.1111/j.1365-2621.2010.02321.x

Gikas, E., Koulakiotis, N. S., Tsarbopoulos, A. (2021). Phytochemical Differentiation of Saffron (Crocus sativus L.) by High Resolution Mass Spectrometry Metabolomic Studies. Molecules, 26(8), 2180. https:/ / doi.org/10.3390/molecules26082180

Giorgi, A., Pentimalli, D., Giupponi, L., Panseri, S. (2017). Quality traits of saffron (Crocus sativus L.) produced in the Italian Alps. Open Agriculture, 2(1), 52-57. https:// doi.org/10.1515/opag-2017-0005

Isfahani S. M. M., et al. (2013). Concentration of crocin, picrocrocin and safranal in Crocus sativus L. under different methyl jasmonate treatment. Technical Journal of Engineering and Applied Sciences, 3669-3673.

Jan, S., Wani, A., Kamili, A. N., Kashtwari, M. (2014). Distribution, chemical composition and medicinal importance of saffron (Crocus sativus L.). African Journal of Plant Science, $8(12), 537-545$.

Katawazy, A. S. (2013). A Comprehensive Study of Afghan Saffron. Report of Research, Planning and Policy Directorate, Afghanistan Investment Support Agency.

Kiani, S., Minaei, S., Ghasemi-Varnamkhasti M. (2018). Instrumental approaches and innovative systems for saffron quality assessment. Journal of Food Engineering. 216, 110. https:// doi.org/10.1016/j.jfoodeng.2017.06.022 
Korani, S., Korani, M., Sathyapalan, T., Sahebkar, A. (2019). Therapeutic effects of Crocin in autoimmune diseases: A review. BioFactors, 45(6), 835-843. https:// doi.org/10.1002/biof.1557

Lage, M., Cantrell, C. L. (2009). Quantification of saffron (Crocus sativus L.) metabolites crocins, picrocrocin and safranal for quality determination of the spice grown under different environmental Moroccan conditions. Scientia Horticulturae, 121(3), 366-373. https:// doi.org/10.1016/j.scienta.2009.02.017

Lee, F. Y., Htar, T. T., Akowuah, G. A. (2015). ATR-FTIR and Spectrometric Methods for the Assay of Crocin in Commercial Saffron Spices (Crocus savitus L.). International Journal of Food Properties, 18(8), 1773-1783. doi:10.1080/10942912.2014.923911

Lozano, P., Castellar, M. R., Simancas, M. J., Iborra, J. (1999). A quantitative high-performance liquid chromatographic method to analyse commercial saffron (Crocus sativus L.) products. Journal of Chromatography A, 830(2), 477-483. https:/ / doi.org/10.1016/S00219673(98)00938-8

Maggi, L., Sanchez A. M, Carmona, M., et al. (2011). Rapid determination of safranal in the quality control of saffron spice (Crocus sativus L.). Food Chemistry, 127(1), 369-373. https:// doi.org/10.1016/j.foodchem.2011.01.028

Manzo, A., Panseri, S., Bertoni, D., Giorgi, A. (2015). Economic and Qualitative Traits of Italian Alps Saffron. Journal of Mountain Science, 12, 1542-1550. doi: 10.1007/s11629-015-34483

Melnyk, J. P., Wang, S., Marcone, M. F. (2010). Chemical and biological properties of the world's most expensive spice: Saffron. Food Research International, 43(8), 1981-1989. https:// doi.org/10.1016/j.foodres.2010.07.033

Padmavathy, J., Kumar, C. P., Saraswathi, S., et al. (2011). Pharmacological, Pharmacognostic and Phytochemical Review of Saffron. International Journal of Pharmacy \& Technology, $3(3), 1214-1234$.

Peter, W. (2007). Marketing Afghan Saffron. International Research and Development, Washington State University.

Petrakis, E. A., Polissiou, M. G. (2017). Assessing saffron (Crocus sativus L.) adulteration with plant-derived adulterants by diffuse reflectance infrared Fourier transform spectroscopy coupled with chemometrics. Talanta, 162, 558-566. https:// doi.org/10.1016/j.talanta.2016.10.072

Pitsikas, N., Zisopoulou, S., Tarantilis, P. A., Kanakis, C. D., Polissiou, M. G., Sakellaridis, N. (2007). Effects of the active constituents of Crocus sativus L., crocins on recognition and spatial rats' memory. Behavioural Brain Research, 183(2), 141-146. https:// doi.org/10.1016/j.bbr.2007.06.001

Sanchez, A. M., Carmona, M., del Campo, C. P., Alonso, G. L. (2009). Solid-phase Extraction for Picrocrocin Determination in the Quality Control of Saffron Spice (Crocus sativus L.). Food Chemistry, 116(3), 792-798. doi: 10.1016/j.foodchem.2009.03.039

Sanchez, A. M., Carmona, M., Zalacain, A., et al. (2008). Rapid Determination of Crocetin Esters and Picrocrocin from Saffron Spice (Crocus sativus L.) using UV-Visible Spectrophotometry for Quality Control. Journal of Agricultural and Food Chemistry, 56(9), 3167-3175. https:// doi.org/10.1021/jf703725e 
Sereshti, H., Heidari R., Samadi, S. (2014). Determination of volatile components of saffron by optimized ultrasound-assisted extraction in tandem with dispersive liquid-liquid microextraction followed by gas chromatography-mass spectrometry. Food Chemistry, 143, 499-505. https:// doi.org/10.1016/j.foodchem.2013.08.024

Sereshti, H., Poursorkh, Z., Aliakbarzadeh, G., et al. (2018). An image analysis of TLC patterns for quality control of saffron based on soil salinity effect: A strategy for data (pre)$\begin{array}{llll}\text { processing. } & \text { Food } & \text { 8hemistry, }\end{array}$ https:/ / doi.org/10.1016/j.foodchem.2017.07.012

Sujata V., Ravishankar, G. A., Venkataraman, L. V. (1992). Methods for the analysis of the saffron metabolites crocin, crocetins, picrocrocin and safranal for the determination of the quality of the spice using thin-layer chromatography, high-performance liquid chromatography and gas chromatography. Journal of Chromatography, 624(1-2), 497-502. https:// doi.org/10.1016/0021-9673(92)85699-T

Tsatsaroni, E. G., Eleftheriadis, I. C. (2008). The colour and fastness of natural saffron. Journal of the Society of Dyers and Colourists, 110(9), 313-315. doi:10.1111/j.14784408.1994.tb01666.x

Wang, Y., Han, T., Zhu, Y., Zheng, C.-J., Ming, Q.-L., Rahman, K., Qin, L.-P. (2010). Antidepressant properties of bioactive fractions from the extract of Crocus sativus L. Journal of Natural Medicines, 64, 24. https:/ / doi.org/10.1007/ s11418-009-0360-6

Zalacain, A., Ordoudi, S. A., Díaz-Plaza, E. M., Carmona, M., Blázquez, I., Tsimidou, M. Z., Alonso, G. L. (2005). Near-infrared spectroscopy in saffron quality control: Determination of chemical composition and geographical origin. Journal of Agricultural and Food Chemistry, 53(24), 9337-9341. https:/ / doi.org/10.1021/jf050846s

Zougagh, M., Rios, A., Valcarcel, M. (2006). Determination of total safranal by in situ acid hydrolysis in supercritical fluid media: Application to the quality control of commercial saffron. Analytica Chimica Acta, 578(2), 117-121. https:// doi.org/10.1016/j.aca.2006.06.064 